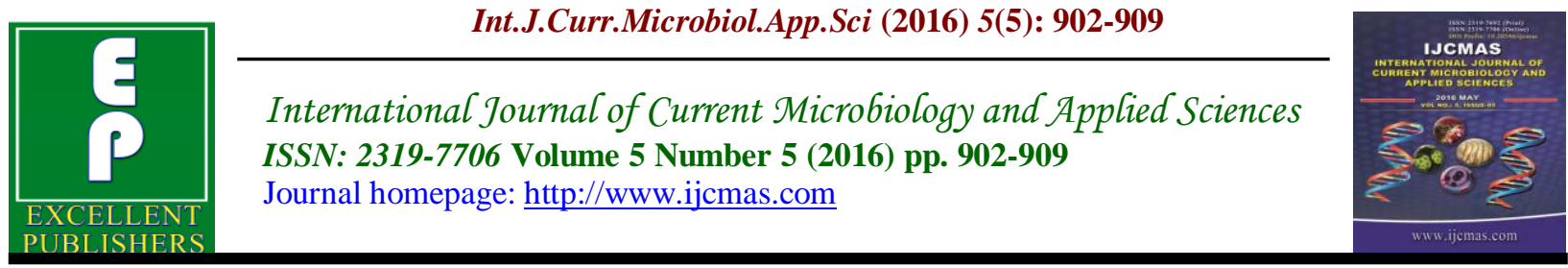

Original Research Article

http://dx.doi.org/10.20546/ijcmas.2016.505.093

\title{
Isolation, Characterization and Optimization of Lipase Producing Pseudomonas spp. from Oil Contaminated Sites
}

\author{
B.N. Shukla ${ }^{1 *}$ and P.V. Desai ${ }^{2}$ \\ ${ }^{1}$ Department of Microbiology, Arts, Science and Commerce College- Kholwad; Kamrej Char \\ Rasta, Surat (Gujarat), India \\ ${ }^{2}$ Department of Biosciences, VNSG University, Surat (Gujarat), India \\ *Corresponding author
}

\begin{tabular}{ll}
\hline \multirow{2}{*}{$\begin{array}{l}\text { Keywords } \\
\begin{array}{l}\text { Tributyrine agar } \\
\text { plate, }\end{array}\end{array}$} & $\begin{array}{l}\text { This study aims to isolate different bacteria characterize and screen them for } \\
\text { the production of lipase. Total eight different bacterial isolates showing } \\
\text { Lipase activity. }\end{array}$ \\
\cline { 1 - 1 } $\begin{array}{l}\text { Article Info } \\
\text { good extracellular lipase activity were isolated on tributyrin agar plates from } \\
\text { oil contaminated sites. Out of which BN-2 showed moderate lipase activity } \\
\text { in the production medium (basal medium) using olive oil as substrate. }\end{array}$ \\
$\begin{array}{ll}\text { Accepted: } \\
\text { Available Online: } \\
\text { 10 May 2016 }\end{array}$ & $\begin{array}{l}\text { Lipase activity was quantified spectrophotometrically at } 410 \mathrm{~nm} \text {. Effect of } \\
\text { different pH, temperature and various carbon sources was optimized and } \\
\text { lipase activity was assayed. }\end{array}$ \\
\hline
\end{tabular}

\section{Introduction}

Ecosystem, including human communities, are facing major problems with release of quantities of oil pollutants each year as a result of human activities. In some cases, these releases are deliberate and well regulated (e.g. Industrial emissions), while in other cases, they are accidental and largely unavoidable (e.g. chemical spills) (Akpofure et al., 2000).Fats and oils (i.e. "grease", defined as plant oil / animal fats) are among the stable organic compounds in wastewater. Fats and oils have been discharged from various industries (i.e. food, chemical, pharmaceutical, cosmetic, leather and detergent), restaurants, slaughter house, and households (Becker et al., 1999; Stoll and Gupta, 1997).
High concentration of these compounds in wastewater often causes major problem in wastewater treatment process. Because of their low density and spreading nature, they will form layer on water surface and decrease oxygen transfer rate in to the aerobic process (Becker et al., 1999). The release of such compounds into water bodies is undesirable for photosynthesis of aquatic plants and creates eutrophication.

The interest in microbial lipase production has increased in the last decades, because of its large potential in industrial applications (Eliboland Ozer, 2001; Kamini et al., 2000). Lipases are available from many sources however, the most suitable sources for lipase 
production are microbes including bacteria, fungi and yeast. These microorganisms can produce high quality lipases in lower cost and shorter time (Trichel et al., 2010). Microbial lipases constitute an important group of biotechnologically valuable enzymes, mainly because of the versatility of their applied properties and ease of mass production (Suzuki et al., 1988, Macrae A.R. 1983). Besides their industrial applications, novel biotechnological applications have been successfully established using lipases for the synthesis of biopolymers and biodiesel, the production of enantiopure pharmaceuticals, agrochemicals and flavor compounds (Jaeger et al., 2002). Because of huge variation in applications, the availability of lipases with specific characteristics is still a limiting factor. They are different from one another in their physical and biochemical properties. Different industrial applications require different properties of lipase, so there is some interest in searching of a new lipase (Jaeger et al., 1994).

Thus, to search for new lipases with different characteristics continue to be important research topic.Majority of microbial lipases are extracellular and are usually secreted out in the culture medium, although there are a few reports of the presence of intracellular lipases (Mourey 1981, Lee and Lee 1989) as well as cell bound lipases (Large et al., 1999).

Bacterial lipases are mostly inducible enzymes, requiring some form of oil, fatty acid, fatty acid alcohol or fatty acid ester for induction (Shah et al., 2011). However, there are a few reports of constitutive lipase production by bacteria (Elwan et al., 1983, Gao et al., 2000). Lipases are usually secreted out in the culture medium, but membrane bound lipases and intra-cellular lipases have been reported (Pandey et al.,
1999).The onset of lipase production is organism specific but in general, it is released during late logarithmic or stationary phase (Matselis and Roussis 1992, Makhzoumetal, Ghosh et al., 1996).Lipase production is influenced by the type and concentration of carbon and nitrogen sources, the culture $\mathrm{pH}$, the growth temperature and the dissolved oxygen concentration (Elibol and Ozer 2001). Olive oil is the most used lipid substrate to induce lipase production by bacteria (Rathi et al., 2002).

The aim of this study was to identify and investigate the role of lipase produced by microorganisms and optimize the various parameters for its production. Microbial lipases have gained special industrial attention due to their stability, selectivity, and broad substrate specificity. Microbial enzymes are also more stable than their corresponding plant and animal enzymes and their production is more convenient and safer (Larbidaouadi et al., 2014). Many lipases show varied substrate and positional specificities and find use in various industries like food, pharmaceutical, detergent, dairy (Balakrishnan et al., 2011), cosmetic, perfumes, biodiesel chemical (Boonmahome et al., 2013), paper and leather.(Shirisha et al., 2010).

There are abundant methods available for lipase activity estimation and they have been well reviewed in the literature (Jaeger et al., 1994). Most of these methods are designed to estimate the products of hydrolytic reactions. These assay methods can be classified as

1.Titrimetry,

2.Interfacial tensiometry,

3.Spectroscopy (Photometry, fluorimetry, 
Infrared and turbidimetry)

\section{Chromatography}

5.Immunochemistry and

6.Conductimetry.

\section{Materials and Methods}

\section{Sample Collection}

Sample was collected at Shanidev oil mill nearby Batliboi Co. at Udhana in the South Gujarat region of Gujarat state from the waste material remains after the deoiling of groundnuts..

Organisms were isolated on tributyrine agar plates from oil contaminated sites and stored at $4^{\circ} \mathrm{C}$ on agar slants and glycerol stocks. Eight colonies were obtained out of which isolate $\mathrm{BN}-2$ was further tested.

\section{Inoculum Preparation}

In order to prepare the inoculum, a loopful of cells from a freshly grown slant was transferred into a $250 \mathrm{ml}$ conical flask containing $50 \mathrm{ml}$ of minimal media (without agar) $\mathrm{KH}_{2} \mathrm{PO}_{4}-3.0 \mathrm{~g}, \mathrm{Na}_{2} \mathrm{HPO}_{4-} 6.0 \mathrm{~g}$, NaCl- $5.0 \mathrm{~g}, \mathrm{NH}_{4} \mathrm{Cl}-2.0 \mathrm{~g}, \mathrm{MgSO}_{4}-0.1 \mathrm{~g}$ in 1 litre of distilled water and incubated at $30^{\circ} \mathrm{C}$ in a shaking incubator at $180 \mathrm{rpm}$ for $24 \mathrm{~h}$ (Oswal et al., 2002).

Lipase assay medium (peptone-30, $\mathrm{NaH}_{2} \mathrm{PO}_{4}-12, \mathrm{KH}_{2} \mathrm{PO}_{4}-2, \mathrm{MgSO}_{4} .7 \mathrm{H}_{2} \mathrm{O}-0.3$, $\mathrm{CaCl}_{2}-0.25$, olive oil-10 g /L) at $\mathrm{pH} 7$ was used for enzyme assay.

\section{Lipase Assay}

The crude enzyme obtained from centrifugation was assayed for lipase activity. The activity of lipase was determined as described in literature
(Winkler and Stuckman, 1979) with the following modification, $10 \mathrm{ml}$ of isopropanol containing $30 \mathrm{mg}$ of p-nitro phenyl acetate was mixed with $90 \mathrm{~mL}$ of $0.05 \mathrm{M}$ of Sorenson phosphate buffer $(\mathrm{pH}$ 8.0), containing $207.0 \mathrm{mg}$ of sodium deoxycholate and $100 \mathrm{mg}$ of Gum acacia.

According to this method a $2.4 \mathrm{~mL}$ of freshly prepared p-nitro phenyl acetate substrate solution was mixed with $0.1 \mathrm{~mL}$ of crude enzyme. After 15 min of incubation at $15^{\circ} \mathrm{C}$, optical density was measured at 410 $\mathrm{nm}$ against an enzyme free control. One unit of lipase activity is defined as the amount of enzyme releasing $1 \mu$ mole p-nitro phenol per minute under assay conditions.

Lipase activity was determined at different time intervals such as $24 \mathrm{hrs}$, $48 \mathrm{hrs}$ to $96 \mathrm{hrs}$

\section{Optimization of Various Physical Parameters for Lipase Production}

The growth of the isolate was carried out in media having $\mathrm{pH}$ ranging from5 to9. The assay media were incubated at various temperatures ranging from 27 to $45^{\circ} \mathrm{C}$, andCarbon sources like coconut oil, groundnut oil, mustard oil, olive oil and sunflower were used.

\section{Results and Discussion}

Total eight bacterial and one fungal isolate showing good extracellular lipase activity were isolated on tributyrine agar plates from oil contaminated sites. Out of which BN1,BN-2 \& BN-3 bacterial spp. showed maximum lipase activity in the production medium (Basal medium) using olive oil as substrate.

Here we describe the study of isolate $\mathrm{BN}-2$ which gave the following colonial morphology on plating. The colonies were large, lobed, smooth, slightly raised, 
translucent and pigmented. The Gram reaction showed pink colored gram negative rods.

The other special staining characteristics and biochemical reactions are as shown in Table:
1 A \&B. The organism was then identified by 16 rRNA sequencing. The sequence was submitted to Genbank and was given the Acc.No.KP-307769. The BLAST results gave $99 \%$ similarity with Pseudomonasspp. The sequence is as shown in the Figure1.

Table.1A Biochemical Reactions of the Bacterial Isolate BN-2

\begin{tabular}{|l|l|l|}
\hline Sr. No. & \multirow{2}{*}{ Bio chemical property } & Results \\
\cline { 3 - 3 } & & BN-2 \\
\hline 1 & Indole production & Negative \\
\hline 2 & Methyl red test & Negative \\
\hline 3 & VogesProskauer & Negative \\
\hline 4 & Citrate utilization & Negative \\
\hline 5 & $\mathrm{H}_{2}$ S production & Negative \\
\hline 6 & Glucose utilization & Positive \\
\hline 7 & Lactose utilization & Negative \\
\hline 8 & Maltose utilization & Negative \\
\hline 9 & Mannitol utilization & Negative \\
\hline 10 & Xylose utilization & Negative \\
\hline 11 & Fructose utilization & Positive \\
\hline 12 & Oxidase activity & Negative \\
\hline 13 & Deaminase activity & Negative \\
\hline 14 & Catalase activity & Positive \\
\hline 15 & Urease & Positive \\
\hline 16 & Gelatinase & Positive \\
\hline 17 & Starch utilization & Negative \\
\hline
\end{tabular}

Table.1B Selected Special Staining and Characteristics of the Isolate.

\begin{tabular}{|l|l|l|}
\hline Sr. No. & Special Characteristics & Results \\
\cline { 3 - 3 } & & BN-2 \\
\hline 1 & Spore & Absent \\
\hline 2 & Capsule & Absent \\
\hline 3 & Growth on kings agar plate & $\begin{array}{l}\text { Produce pale yellow } \\
\text { pigment }\end{array}$ \\
\hline 4 & Response to oxygen & Strictly aerobic \\
\hline 5 & Growth at $4{ }^{5} \mathrm{C}$ temperature & Negative \\
\hline 6 & Growth at $40^{\circ} \mathrm{C}$ temperature & Negative \\
\hline
\end{tabular}


Fig.1 BN2_907R_S012604_E11+R.abi: Data obtained with Reverse primer >BN-2_704F_S012604_G0-(818bp)

TTTTTTTAGCCCTCTTCTTGAGATCACCCCCGTCATGAATCACACCGTGGTAACCGTCCTCCC GAAGGTTAGACTAGCTACTTCTGGGTGCAACCCACTCCCCATGGTGTGACGGGCGGTGGTGT ACAAGGCCCGGGAACGTTATTCAACCGGGGACAATTTTGAACTCGGCGATTACTAGCGATTC CGACTTCACGCAGTCGAGTTGCAGACTGCGATCCGGACTACGATCGGTTTTATGGGATTAGC TCCACCTCGCGGCTTGGCAACCCTCTGTACCGACCATTGTAGCACGTGTGTAGCCCAGGCCG TAAGGGCCATGATGACTTGACGTCATCCCCACCTTCCTCCGGTTTGTCACCGGCAGTCTCCTT AGAGTGCCCACCATTACGTGCTGGTAACTAAGGACAAGGGTTGCGCTCGTTACGGGACTTAA CCCAACATCTCACGACACGAGCTGACGACAGCCATGCAGCACCTGTCTCAATGTTCCCGAAG GCACCAATCCATCTCTGGAAAGTTCATTGGATGTCAAGGCCTGGTAAGGTTCTTCGCGTTGC TTTGAAATTAAACCCCATGCTCCACCGCTTGTGCGGGCCCCCGTCAATTCATTTGAGTTTTAA CCTTGCGGCCGTACTCCCCAGGCGGTCAACTTAATGCGTTAGCTGCGCCACTAAAAGCTCAA GGCTTCCAACGGCTAGTTGACATCGTTTACGGCGTGGACTACCAGGGTATCTAATCCTGTTT GCTCCCCACGCTTTCGCACCTCAGTGTCAGTATTAGTCCAGGTGGTCGCGT-CGCC-CAGCGGTTACTTC

>BN2_907R_S012604_E11+(1006bp)

AGTTTG-G-C-G-ACTCCCCAGGCGGTCA-

CTTAGTGCGTTAGCTGCGCCACTAAAAGCTCAAGGCTTCCAACGGCTAGTTGACATCGTTTA CGGCGTGGACTACCAGGGTATCTAATCCTGTTTGCTCCCCACGCTTTCGCACCTCAGTGTCAG TATTAGTCCAGGTGGTCGCCTTCGCCACTG-GTGTTCCTTCCTATATCTACG

CATTTCACCGCTACACAGGAAATTCCACCACCCTCTACCATACTCTAGTCAGTCAGTTTTGAA TGCAGTTCCCAGGTTGAGCCCGGGGATTTCACATCCAACTTAACAAACCACCTACGCGCGCT TTACGCCCAGTAATTCCGATTAACGCTTGCACCCTCTGTATTACCGCGGCTGCTGGCACAGA GTTAGCCGGTGCTTATTCTGTCGGTAACGTCAAAATTGCAGAGTATTAATCTACAACCCTTCC TCCCAACTTAAAGTGCTTTACAATCCGAAGACCTTCTTCACACACGCGGCATGGCTGGATCA GGCTTTCGCCCATTGTCCAATATTCCCCACTGCTGCCTCCCGTAGGAGTCTGGACCGTGTCTC AGTTCCAGTGTGACTGATCATCCTCTCAGACCAGTTACGGATCGTCGCCTTGGTGAGCCATT ACCCCACCAACTAGCTAATCCGACCTAGGCTCATCTGATAGCGCAAGGCCCGAAGGTCCACT GCTTTCTCCCGTATGACGTATGCGGTATTAGCGTCCGTTTCCGAACGTTATCCCCCACTACCA GGCAGATTCCTAGGCATTACTCACCCGTCGGCCGCCTCTCAAGAGAAGCAAGCTTCTCTCTA CCGCTCGACTTGCATGTGTTAGGCCTGCCGCCAGCGTTCAATCTGAGCAGAAAAAAAAAATT CTATTACCCGGAAAAAAAAAATGGGGCGGGGTGGGTTGTTTTTTTAATTACATTCAAAAACT ATACTGCTCTCTTGGTTTTGACGTGCGTTTGCAGATATCGAATGTTGGCCT

Fig.2 Effect of Various pH on Lipase Enzyme Activity

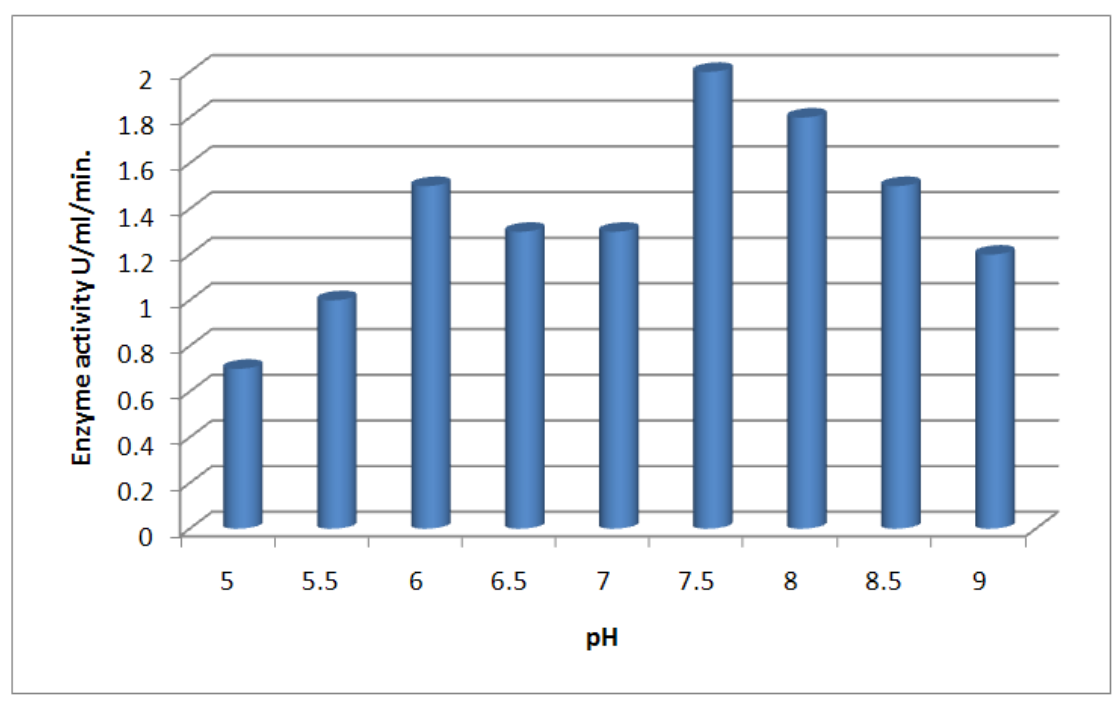


Fig.3 Effect of Temperature

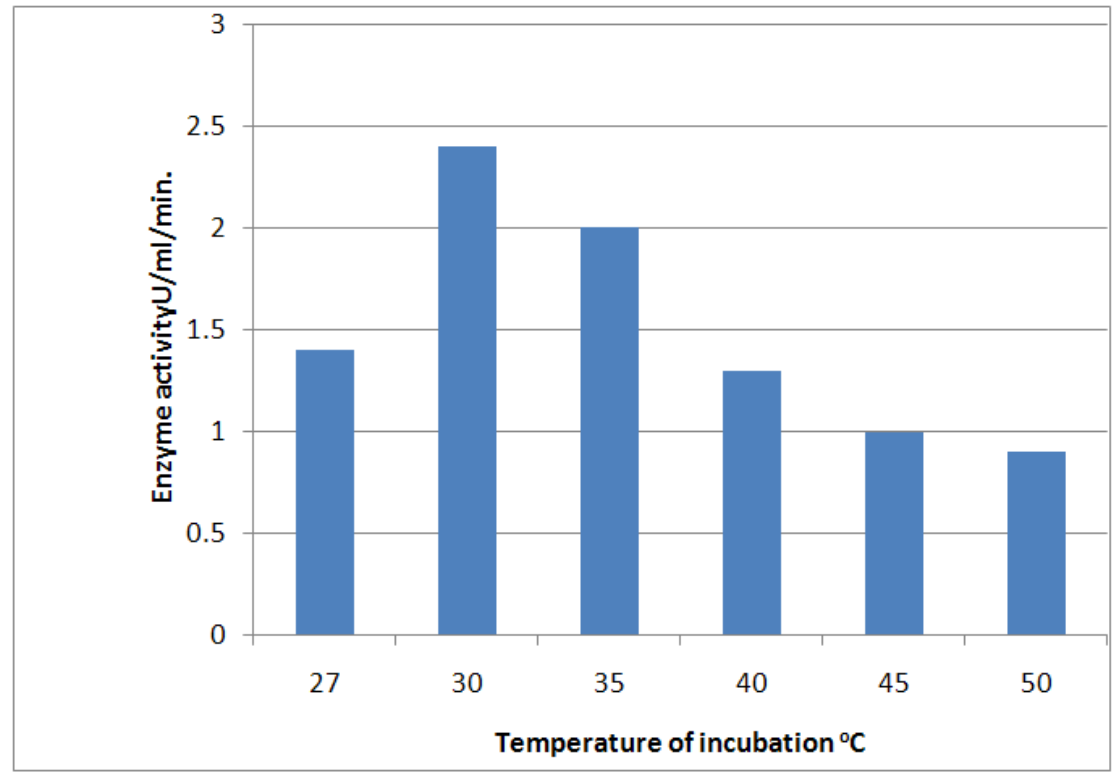

Fig.4 Effect of Various Carbon Sources on Enzyme Activity

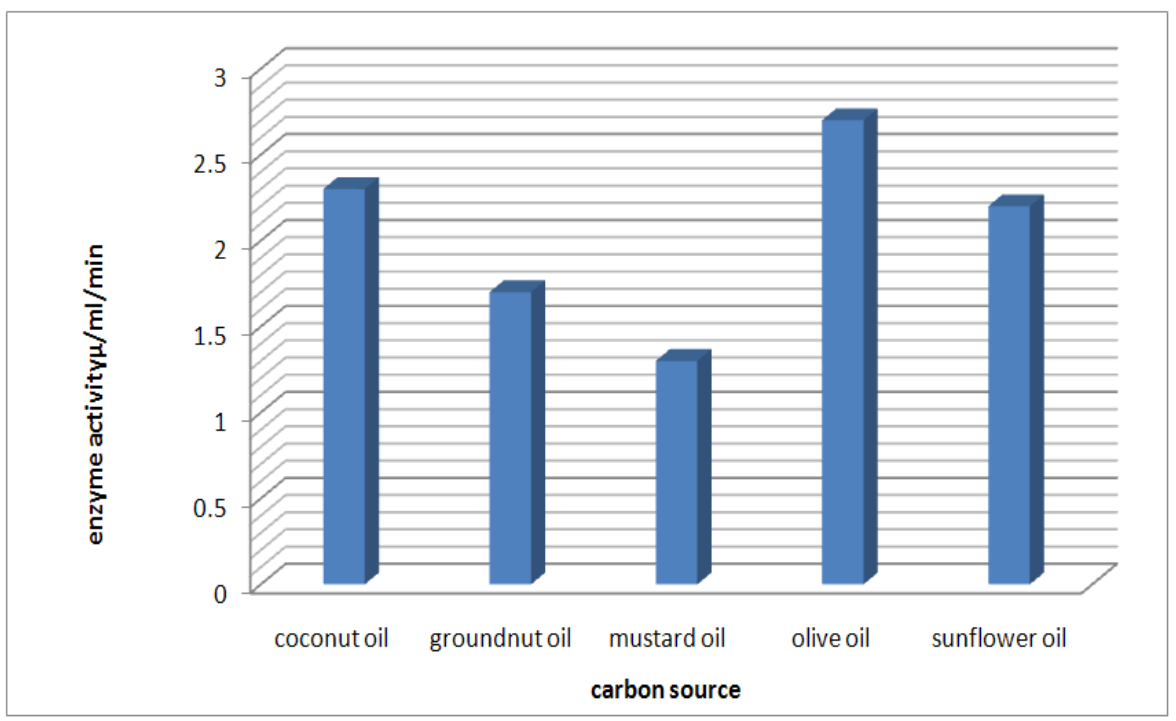

The effect of various $\mathrm{pH}$ on the lipase production showed that $\mathrm{pH} 7.5$ gave optimum lipase activity as shown in Figure: 2. Figure3 shows the effect of various temperatures of incubation on the microbial lipase activity. When analysed for the various carbon sources as substrates the bacterial isolate $\mathrm{BN}-2$ showed good activity when using olive oil as substrate (Figure:4).
In conclusion, the present study say that due to the increasing demand of lipases in the global market, searching for new and highly efficient microbial lipases is a difficult task. Here we have tried to isolate such lipase producing organism that has been identified as Pseudomonas spp. Acc. No.KP-307769. From above study it has been found that the isolated organism $\mathrm{BN}-2$ shows maximum 
activity $2.7 \mathrm{U} / \mathrm{ml} /$ minute at $\mathrm{pH} 7.5,30^{\circ} \mathrm{C}$ temperature, and $2 \%$ olive oil concentration. after 48 hours to 72 hours.

\section{References}

Akpofure, E.A., M.L., Ayawei, P. 2000. The adverse effects of crude Oil Spills in the Niger Delta Urhobo Historical society.

Balakrishnan Padmapriya, Thamaraichelvan Rajeswari, Ereelot Noushida. 2011. Production of Lipase Enzyme from Lactobacillus spp. and its Application in the Degradation of Meat. World Appl. Sci. J., 12(10): 1798-1802.

Becker, P., Koster, D., Popov, M.N., Markossian, S., Antranikian, G., Markl, H. 1999.

Boonmahome, P., WiyadaMongkolthanaruk. 2013. Lipase-Producing Bacterium and its Enzyme Characterization. $J$. Life Sci. Technol., Vol. 1, No. 4.

Elibol, M., Ozer, D. 2001. Influence of oxygen transfer on lipase production by Rhizopus arrhizus, Process Biochem., 36: 325-329.

Elwan, S.H. et al. 1983. Lipase production by Bacillus circulans under mesophilic and osmophilic conditions. Factors affecting lipase production. $G$. Bacterio Viro lmmuno., 76(7-12): 187199.

Gao, X.G., et al. 2000. Production, properties and application to nonaqueous catalysis of lipase from a newly isolated Pseudomonas strain. Enzym. Microb. Technol., 27: 74-82.

Ghosh, P.K., Saxena, R.K., Gupta, R., Yadav, R.P., Davidson, S. 1996. Microbial Lipases: Production and applications, Sci. Prog., 79: 119-157.

Jaeger, K.E., Ransac, S., Dijkstra, B.W., Colson, C., van Heuvel, M., Misset, O. 1994. Bacterial lipases. Microbiol. Rev., 15: 2963.
Jaeger, K.E., Eggert, T. 2002. Lipases for biotechnology. Cur. opi. Biotechnol., 13: 390-397.

Kamini, N.R., Fuji, T., Kurosu, T., Iefuji, H. 2000. Production, purification and characterization of an extracellular lipase from the yeast, Cryptococcus $s p$ S2. Process Biochem., 36: 317-324.

Larbidaouadi, K., Benattouche, Z., Bbouni, B.A. 2014. Screening selection identification production and optimization of bacterial lipase isolated from industrial rejection of gas station J. Chem. Pharma. Res., 6(6): 455-459.

Large, K.P., Mirjalili, N., Peacock, M.O.L.M., Zormpaidis, V., Walsh, M., Cavanagh, M.E., Leadlay, P.F., Ison, A.P. 1999. Lipase activity in Streptomycetes. Enzym. Microb. Technol., 25(7): 569-575.

Lee, S.Y., Lee, B.H. 1989. Production and characterization of esterase-lipase of Lactobacillus caseisupsp. Pseudo plantarum LE2. Biotechnol. Appl. Biochem., 11: 552-563.

Macrae, A.R. 1983. Lipase catalyzed interesterfication of oils and fats. $J$. Am. oil Chem. Soc., 60: 291-294.

Makhzoum, A., et al. 1995. Factors affecting growth and extracellular lipase production by Pseudomonas fluorescens 2D. Fd. Microbiol., 12(4): 277-290.

Matselis, E., Roussis, I.G. 1992. Influence of culture conditions and hydrogen peroxide on growth and extracellular enzyme production by Pseudomonas UICD31. Fd. Sci. Technol., 25(5): 433-437.

Mourey, A. 1981. Lipolytic activity of Bacillus pumilus. Rev.Fr. Corps Gras, 28(2), 55-8 (French). CA, 94: 188319.

Oswal, N., Sharma, P.M., Zinjarde, S.S., Pant, A. 2002. Palm oil mill effluent treatment by atropical marine yeast, 
Bioresour. Technol., 85: 35-37.

Pandey, A., Benjamin, S., Soccol, C.R., Nigam, P., Krieger, N., et al. 1999. The realm of microbial lipases in Biotechnology, Biotechnol. Appl. Biochem., 29-131.

Shah, K.R., Bhatt, S.A. 2011. purification and characterization of lipase from Bacillus subtilis $\mathrm{Pa} 2$, J. Biochem. Tech., 3(3): 292-295.

Sirisha, E., Rajasekar, N., Lakshmi, M. 2010. Narasu, Isolation and Optimization of Lipase Producing Bacteria from Oil Contaminated Soils (2010). Adv. Biol. Res., 4(5): 249-252.

Stoll, U., Gupta, H. 1997. Management strategies for oiland grease residues. J.Waste Manage.Res., 15: 23-32.

Suzuki, T., Mushiga, Y., Yamane, T.,
Shimizu, S. 1988. Mass production of lipase by fed-batch culture of Pseudomonas fluorescens. Appl. Microbiol. Biotechnol., 27: 417-422.

The biodegradation of olive oil and the treatment of lipid-rich wool scouring wastewater under aerobic thermophilic conditions. Water Res., 33:653-660.

Trichel, H., Oliveira, D., Mazutti, M.A., Luccio, M.D., Oliveira, J.V. 2010. A review on microbial lipases production. Food Bioprocess Technol., 3: 182-196.

Winkler, U.K., Stuckmann, M. 1979. Glycogen hyaluronate and some other polysaccharides greatly enhance the formation of exolipase by Serratia marcescens. J. Bacteriol., 138(3): 663.

\section{How to cite this article:}

Shukla, B.N. and Desai, P.V. 2016. Isolation, Characterization and Optimization of Lipase Producing Pseudomonas spp. from Oil Contaminated Sites. Int.J.Curr.Microbiol.App.Sci. 5(5): 902-909. doi : http://dx.doi.org/10.20546/ijcmas.2016.505.093 